\title{
Memória das políticas e práticas em redução de danos: entrevista com Fátima Machado
}

\author{
Memory of policies and practices in harm reduction: \\ an interview with Fatima Machado
}

Entrevista com

\section{Fátima Machado}

i in memoriam

Concedida a

Luciane Raupp ${ }^{i i}$

ii Pós-doutoranda, Programa de Pós-graduação em Psicologia/ Universidade Federal de Santa Catarina; presidente, Associação Brasileira Multidisciplinar de Estudos sobre Drogas (Abramd). Florianópolis - SC - Brasil orcid.org/0000-0002-5696-1754 lucianemraupp@gmail.com

\section{Carla Nunes Weberii}

iii Mestre pelo Programa de Pósgraduação em Memória Social e Bens Culturais/Universidade La Salle. Canoas - RS - Brasil

orcid.org/0000-0003-4514-9733

carla.nunesweber@gmail.com

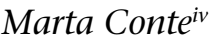 \\ iv Psicanalista. \\ Porto Alegre - RS - Brasil \\ orcid.org/0000-0002-6644-6713 \\ martacte@gmail.com}

Recebido em 9 out. 2019

Aprovado em 17 set. 2020.
RAUPP, Luciane; WEBER, Carla Nunes; CONTE, Marta. Memória das políticas e práticas em redução de danos: entrevista com Fátima Machado. História, Ciências, Saúde - Manguinhos, Rio de Janeiro, v.28, n.3, jul.-set. 2021, p.839-847.

\section{Resumo}

A entrevista aborda a trajetória das políticas e práticas de redução de danos no Brasil por meio do depoimento da redutora de danos Fátima Machado. A perspectiva de redução de danos surgiu na Europa, na década de 1980, e no Brasil iniciou em 1989, como estratégia de prevenção à aids entre usuários de drogas injetáveis, e depois se diversificou e ampliou. A entrevista focaliza os anos iniciais de desenvolvimento dessas práticas inovadoras e problematiza seus desdobramentos atuais. Fátima Machado foi uma das precursoras no trabalho de campo e ativismo da redução de danos no Brasil e uma das fundadoras da Associação Brasileira de Redutores de Danos.

Palavras-chave: redução de danos; aids; políticas públicas; ativismo social; Fátima Berenice de Azevedo Machado (1969-2019).

\section{Abstract}

This interview addresses the trajectory of harm reduction policies and practices in Brazil, in the words of harm reducer Fatima Machado. Harm reduction emerged in the 1980s in Europe, it began in Brazil in 1989 as a strategy to prevent aids among injection drug users, and then diversified and expanded. This interview focuses on the early years of developing these innovative practices and questions their current developments. Fatima Machado was one of the precursors working in the field and in activism for harm reduction in Brazil, and one of the founders of the Brazilian Association of Harm Reducers.

Keywords: harm reduction; aids; public policies; social activism; Fatima Berenice de Azevedo Machado (1969-2019). 
$\mathrm{A}$ entrevista aqui apresentada aborda parte importante da trajetória de implantação e desenvolvimento das políticas e práticas de redução de danos voltadas para pessoas que usam drogas no Brasil, em especial no Rio Grande do Sul, local onde nasceu Fátima Berenice de Azevedo Machado, conhecida como Fátima Machado. A entrevistada foi redutora de danos, ativista social e uma das precursoras no trabalho de campo em cenas abertas de uso de drogas. A entrevista foi realizada na Escola de Saúde Pública do Rio Grande do Sul, para o projeto "Memória e panorama atual da estratégia de redução de danos na Região Sul do Brasil", vinculado ao Programa de Pós-graduação em Memória Social e Bens Culturais da Universidade La Salle, de Canoas (RS), o qual visou produzir registros memoriais da atuação de redutoras e redutores de danos no estado.

A perspectiva de redução de danos sociais e à saúde (RD) teve como experiência precursora a divulgação do Relatório Rolleston, em 1926, na Inglaterra, quando um grupo de médicos afirmava que a maneira mais adequada de tratar dependentes seria por meio de uma administração monitorada, de forma a aliviar os sintomas de abstinência (Brasil, 2003). Nos anos 1960, programas de substituição de heroína por metadona já demonstravam efetividade em estabilizar a vida de usuários dependentes. Em 1980, na busca de soluções diante do aumento de dependentes de heroína ocorrido durante a década de 1970, surgiram experiências pioneiras na Inglaterra e na Holanda nas quais, pela primeira vez, programas de redução de danos ofereceram troca de seringas usadas por novas e estéreis, terapia, emprego e abrigo para usuários de drogas injetáveis (Kleiman, Hawdon, 2011).

No Brasil a RD como prática de saúde pública surge em 1989, na cidade paulista de Santos - a primeira a dirigir ações de prevenção à aids entre usuários de drogas injetáveis, com a criação do primeiro programa de troca de seringas da América do Sul (Petuco, 2019). Posteriormente, ampliou-se, passando a ser considerada uma ética de cuidado, estratégia clínico-política e diretriz de trabalho junto a usuários de drogas (Brasil, 2003; Adamy, Silva, 2017). A partir de 2003 foi incorporada pela política do Ministério da Saúde para atenção a usuários de álcool e outras drogas como diretriz central (Brasil, 2003).

Fátima Machado destacou-se como uma das redutoras de danos pioneiras da cidade de Porto Alegre, que implantou o primeiro Programa de Redução de Danos (PRD) em 1995. A entrevista realizada tem como foco as primeiras décadas de desenvolvimento desse trabalho inovador junto a um público estigmatizado para o qual, até então, as formas de atenção disponíveis exigiam abstinência de drogas e internação em instituições totais. Seu depoimento demonstra o difícil percurso empreendido pelos redutores de danos pioneiros que, de forma criativa e ousada, forjaram, por meio de sua prática, novas formas de ampliar o acesso à saúde e a cidadania de pessoas que usam drogas.

A entrevistada foi sócia fundadora da Associação Brasileira de Redução de Danos (Aborda), entidade não governamental, fundada em 1997, na cidade do Rio de Janeiro. A Aborda surgiu para agregar, defender e qualificar o trabalho de redutoras e redutores de danos, defendendo melhorias em suas condições de vida e trabalho. Participou ativamente das primeiras três diretorias da Aborda e, sem ter formação universitária, ficou nacionalmente conhecida como importante redutora de danos. Foi colaboradora na elaboração da "Agenda estratégica para a ampliação do acesso e cuidado integral das populações-chave em HIV, hepatites virais e outras infecções sexualmente transmissíveis" (Brasil, 2018). 
Fátima Machado faleceu aos 59 anos, no dia 7 de setembro de 2019, depois de lutar contra vários problemas de saúde. Entre seus legados, deixou esta entrevista, realizada um dia antes de sua internação em um hospital onde foi a óbito poucos dias depois. Tendo sido concedida no ano em que a Política Nacional Sobre Drogas foi alterada, retirando a redução de danos de suas diretrizes, destaca-se a importância do material aqui apresentado.

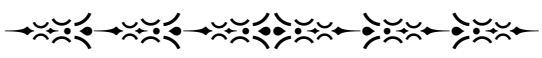

Fátima, obrigada por aceitar conversar com a gente. Você pode nos contar como a redução de danos (RD) entrou na sua vida?

A redução de danos entrou na minha vida em 1997, quando eu estava numa fase totalmente "despencada" com a questão do abuso de drogas. Na época eu usava cocaína injetável. Meu marido estava em uma fase terminal da aids, e eu tive acesso ao Serviço de Assistência Especializada (SAE). Lá havia um doutor muito querido que acompanhou todo o nosso processo, até o dia da perda de meu marido - eu estava com 37 anos. Logo depois disso, o médico me disse que a prefeitura estava implantando um projeto e perguntou se eu queria me engajar. Inicialmente, não haveria remuneração, mas a ideia era que mais tarde seria remunerado, e eu pensei que deveria tentar. O projeto iniciou no bairro Partenon, no Campo da Tuca, em Porto Alegre. O SAE da Vila Cruzeiro era a referência naquela época. Eu fui à primeira reunião.

\section{Você nem sabia o que era RD até então?}

Na verdade, não sabia. Nós construímos as práticas um pouco a partir da minha vivência. Eu já estava fazendo redução de danos comigo, na minha caminhada com o meu marido, só que eu não sabia o nome que se dava àquelas atitudes. Comecei a criar metodologias que me distanciassem do uso problemático. RD é tu criar, a partir de reflexões, de sensibilização, de conscientização, mecanismos que possam te conter, meio que travar, puxar o freio de algumas coisas que estão demais na tua vida. Mesmo que eu não quisesse mais usar, o meu marido insistia. Porque ele dizia que, quando ele usava, o físico dele melhorava. Ele conseguiu ficar três meses sem o álcool, mas desenvolveu depressão, e as doenças evoluíram mais rápido. Ele tinha aids, hepatite $\mathrm{C}$, tuberculose e acabou desenvolvendo hepatite $\mathrm{B}$. Na época, eu acredito que foi uma metodologia de redução de danos buscar todos os recursos possíveis para que ele tivesse o atendimento médico em casa, até mesmo pela debilidade física. Então, eu arrumei esse doutor que fazia parte do programa Adote, de atendimento domiciliar. Ele teve todo esse suporte, mas passaram uns dois meses e ele não aceitava mais a medicação e veio a falecer. Então, no dia $1^{\circ}$ de maio de 1997 eu fui à primeira reunião com o Domiciano Siqueira na Unidade de Saúde São José. Era o início do Programa de Redução de Danos, que ainda estava como projeto-piloto. A ideia do projeto saiu do Setor de DST/Aids do estado em parceria com o Ministério da Saúde e a Cruz Vermelha Brasileira (filial Rio Grande do Sul). Os mentores da parte escrita do programa foram Marta Conte, Fernando Marques, a doutora Nêmora Barcellos, Gerson Winckler e Domiciano Siqueira. 
A partir daí, começou a se pensar na composição de uma equipe que se afinasse com o perfil, para trabalhar em campo.

Então você participou da primeira equipe?

Na verdade, acho que eu entrei numa segunda leva, porque eles começaram em 1996. Antes de mim estavam Dilson Strossi, Domiciano Siqueira e Andrea Felcker.

Eles eram redutores de danos?

Quando começou, não tinha o nome de redutor de danos. Eram monitores de saúde. Quando veio a Associação Brasileira de Redução de Danos, a Aborda, veio tudo meio junto. Ela surgiu em 1998, por meio da articulação do Domiciano Siqueira. Tivemos um encontro em São Paulo, depois juridicamente se estabeleceu como organização não governamental (ONG). Como movimento social surgiu em Brasília, em um encontro na universidade federal em novembro de 1998. A Aborda surgiu meio entrelaçada com o PRD de Porto Alegre. Eu sou fundadora, junto com a Vera Da Ros, o Fábio Mesquita e a Sandra Fergutz Batista. A história da RD começou na Aborda. Nós éramos a Aborda e trabalhávamos com $\mathrm{RD}$, então nós éramos redutores de danos! Foi assim que surgiu a história de ser um agente redutor de danos; já não éramos mais monitores de saúde, porque esse cargo já não fazia mais sentido. A discussão foi feita a nível nacional, assim como a ideia do nome Aborda: a gente trabalhava com abordagem, então vamos dar o nome de Aborda! E dessa região em que a primeira equipe foi criada, em 1997, houve uma ampliação para outras regiões da cidade, com a mesma equipe - não éramos mais do que dez pessoas. O programa foi para dentro da Secretaria Municipal de Saúde e começou a expandir para outras regiões e ampliar, mas sempre com o mesmo número de redutores na equipe.

\section{Qual era a exigência para ser redutor de danos?}

Era ter o perfil. Ser sensível à problemática, ter uma identidade com essas questões.

\section{Era obrigatório que fosse usuário?}

Não, mas que tivesse alguma identificação com o tema. Foi onde houve muitos conflitos, porque quem tinha deixado de usar queria permanecer na preservação de não uso e tinham os que usavam ainda, mas, mesmo assim, fomos tocando. Depois disso, novos foram entrando, e a ideia foi se multiplicando. Passaram várias pessoas por lá: o Dênis Petuco foi um dos redutores de danos na época da Márcia Colombo, na coordenação do PRD em 2000, na época em que eu saí.

\section{Nessa época, onde tinha PRD?}

Em Porto Alegre, acho que só aqui no "postão" da Cruzeiro, que era do município. Acho que em 2007-2008 chegou a ter um pouco mais de trinta PRDs no Rio Grande do Sul, depois foram sendo desmantelados. 


\section{Em qual época começa esse desmonte?}

Mais ou menos na época que teve o Roda Sul. O projeto era uma encomenda do Ministério da Saúde, que queria o fortalecimento da rede dos trabalhadores em RD, bem como o fortalecimento da rede dos usuários. A Aborda executou parte desse projeto, que eram as rodas regionais. Eu trabalhei no Roda Sul e visitei muitos munícipios, e a maioria já estava capengando, tudo se desestabilizando.

\section{E na região metropolitana de Porto Alegre, o que mais tinha de projetos?}

Teve o Viva Mais, que trabalhou com RD. Era uma ONG de pessoas soropositivas, lá trabalhavam a Karen e o Osvaldo Martins. O PRD ficava dentro da ONG Viva Mais, que recebia uma grana do Estado pra fazer projetos na área. A Karen e o Osvaldo eram quem eu conhecia, eles faziam "campo", trabalhavam muito a questão da prostituição, atendiam na ONG, tinham atividades que eles desenvolviam. Essa ONG não existe mais, assim como outras nos municípios. Teve também o Fórum Metropolitano de RD, com a Márcia Colombo, o Ricardo Charão, a Rose Mayer. Só que não vingou porque a militância não existia nessa parte, as pessoas não se envolviam, não protagonizavam. Não era o governo que tinha que estar protagonizando, era o movimento social. E, aí, terminou fechando. Depois veio o Consultório na Rua em 2013-2014. Na última gestão do município de São Leopoldo, o Ricardo Charão estava envolvido com a ONG Apoio, Solidariedade e Prevenção à Aids (Aspaa), que também trabalhava com RD.

\section{Como era tua rotina de trabalho como redutora de danos?}

Era uma convivência com os usuários que eu encarava como uma questão de ir lá e orientar sobre o cuidado de si. Nós tínhamos água destilada, seringa, lencinho, preservativo, informativos e a caixa Descartex, que vinham do Ministério da Saúde. Nós íamos a campo e a gente se vinculava a algum morador que nominávamos de agente-morador porque, como eles estavam na comunidade, tinham facilidade no acesso e vínculo com os usuários. E era por meio deles que a gente ia se vinculando a esses grupos. Eles faziam essa intermediação da troca de seringas, até a gente chegar à população vulnerável. Nós tínhamos muito cuidado na questão da reutilização, de o cara ter a seringa e a Descartex na casa dele e, de repente, chegarem muitas pessoas lá, compartilharem, reutilizarem. Então, a gente optava por ter o agente-morador, que era mais responsável. Então, eles faziam a troca, ficavam com as sujas, e os caras do projeto trocavam as seringas sujas por seringas limpas.

\section{E eles também eram usuários de drogas?}

Não. Geralmente, a gente optava pelos agentes moradores não serem usuários. Porque conheciam o "fulano", "ciclano"... e nós tínhamos esse cuidado, se nós estávamos trabalhando com o não compartilhamento, não reutilização, então a gente não poderia permitir isso. 


\section{Vocês tinham alguma forma de avaliação ou monitoramento do trabalho?}

Não, na verdade a gente foi construindo e percebendo, conforme o contato com eles, o que daria certo ou não. Por isso nós terminamos tendo esse cuidado de não deixar com os usuários, porque a gente começou a perceber o perigo da reutilização. Criamos também as funções e deveres do redutor de danos, que eram as questões de ouvir e de observar - nossa função maior em campo. Direcionar e saber como lidar com fulano, com ciclano, ou no geral. Hoje a gente pode minimamente direcionar algumas metodologias, mas que não servem para todos. Os serviços de dependência química, por exemplo, não funcionam para todos.

\section{Quais eram tuas atribuições dentro do PRD?}

Tinha os horários de plantões. Quando foram ampliados, os plantões eram a semana inteira. No verão, a gente trabalhava de noite, no inverno, a gente trabalhava das $16 \mathrm{~h}$ até umas 19, 20h, mas às vezes eu saía do campo à meia-noite. Depois nós começamos a trabalhar todos os dias. Eu tinha uma função a mais no PRD, comecei a fazer a parte da organização dos usuários de drogas, então eu estava muito mais presente do que os demais companheiros nisso. A organização era a Associação Gaúcha de Redutores de Danos, que surgiu do PRD e da Aborda e lançou as sementinhas de outras ONGs Brasil afora. Faziam parte dela tanto os trabalhadores quanto os usuários. Eu era responsável pela mobilização dos usuários de drogas dentro de Porto Alegre. Eu me doava, era muito militante. Às vezes, eu chegava de manhã e ficava até o pessoal voltar do plantão, descartar a caixa Descartex, e, se sobrasse material, repor no lugar, mesmo quando não era meu plantão. Então, eu sempre fui muito envolvida.

\section{Quem coordenava o PRD?}

Domiciano Siqueira era o coordenador do programa, que em 1998 era um projeto e depois virou programa. Desde o início ele era o coordenador, acho que ele saiu em 2000. Depois que ele saiu, meu nome estava sendo requisitado para ser coordenadora, foi quando saiu a história na revista Veja que escrachou a minha vida na página central. Eles vieram com a ideia de mostrar o trabalho, como é difícil separar a vida pessoal do trabalho, e no meio das perguntas eles questionavam coisas que tinham a ver com a minha vida e, claro, eu falava. Só que aí, inocentemente, eu não me dei conta que poderiam inverter as coisas. Uma semana depois, 5 de agosto de 2000, estava eu lá, linda, maravilhosa, com a Descartex na mão, saindo de um lugar no meio do mato onde o pessoal se abrigava e fazia moradia. $\mathrm{E}$ ali havia várias palavras pejorativas: "Mesmo drogada, Fátima Machado vai a campo, entra em lugares fétidos" ... coisas assim: "Entre a vida e o vício"... Pesadíssimo! Eu não tenho mais ela, muito material que eu guardei durante esses anos se extraviou, com mudanças e outras coisas, só tenho cópias.

\section{Qual foi a época em que você trabalhou no PRD?}

Eu fiquei de 1997 a 2001. Fiquei durante nove anos só no movimento social, só na Aborda e na Rede Gaúcha de Redutores, aí eu me engajei com a história da rede de usuários de 
drogas do RS. Ainda que juridicamente não tivesse acontecido, eu fazia assembleias, o pessoal não vinha, uma série de coisas assim. Então, eu pensei em, quem sabe, aproveitar o CNPJ e transformar em organização de usuários de drogas. A minha ideia era que se os redutores são pessoas que têm problemáticas com drogas, pessoas que vivem excluídas da sociedade, pessoas que são consideradas marginalizadas, então, esse seria o nosso lugar. Por isso nunca me comprometi a estudar, correr atrás, ser acadêmica. Porque eu me envolvi tanto com essas histórias e acreditei tanto que era possível ter essa inserção, de fato, que eu me esqueci de todo o resto, e o tempo passou. E eu não evoluí na questão de estudos acadêmicos, mas eu evoluí em ter total e notório saber na questão da redução de danos. Tem gente que acha que eu sou professora. Eu apenas adquiri conhecimentos que me dão respaldo como referência no Rio Grande do Sul.

Na época em que você estava em campo, pensando na militância, quais eram os desafios?

A polícia. Porque por várias vezes queriam nos levar presos, por causa do material perfurocortante. Era um material proibido, só que a gente tinha como respaldo uma cartinha do Ministério da Saúde que nos apresentava como uma ação do ministério. Então, os policiais se descabelavam e sapateavam com aquelas botinas: "Vamos levar, vamos enquadrar!", e outros: "Não, vamos deixar essa gente, vamos nos incomodar com o governo". Aí eu terminava dizendo: "Olha, vocês vão enquadrar o Ministério da Saúde, não a nós". Em 2010, quando mudou a gestão, entrou a Mirian Weber na Política Municipal de Aids, e ela me chamou de volta. Eu fiquei até 2012, porque houve a eleição, e, em dezembro, quando acabavam nossos contratos, o programa fechou. Tentamos resgatar o caráter anterior do programa, fazer o mapeamento..., e não saiu disso porque não deu tempo.

Você chegou a pegar a transição das drogas injetáveis para o crack, ainda estando no PRD?

Sim, complicadíssimo! Eu tenho um kit de cuidado, que são várias ferramentazinhas: a esmurrugadora, ${ }^{1}$ a piteira, o cachimbinho, a lata amassada, os cachimbos quebrados que a gente pegava para que eles não raspassem os restos que ficavam no cachimbo. Então eu fiz tipo um kit que eu ia apresentando para eles.

Na tua percepção, o crack chega aqui em que época? Vocês começam a se deparar com essa droga e com a diminuição das injetáveis?

Acho que em 2005 começou a estourar. Na verdade, a gente não conseguiu criar vínculo com esse tipo de usuário. Até mesmo porque o programa começou a se desmantelar. Teve uma série de coisas que mudou o caráter do programa, justamente na época que estourou o crack. Com a nova gestão da prefeitura, na época, o PRD virou muito mais comunidade terapêutica do que outra coisa, e se perdeu o vínculo com as comunidades. Hoje, retomar isso no campo vai ser muito difícil. Por exemplo, individualmente, caminhando na rua, a gente até vai conseguir fazer alguma intervenção, mas, acessar o brete, ${ }^{2}$ como antigamente a gente fazia, é inviável. 


\section{E tu notavas resultado das práticas de campo?}

O que eu posso falar é que eu vivenciei a transformação de pessoas na época da injetável. Eu vi muita gente se modificando, correndo atrás de uma nova vida, se desprendendo desse uso, formando famílias. Por exemplo, na época havia duas irmãs, uma não usava injetável, mas cheirava muito, era da prostituição e tudo mais, e a gente tinha um vínculo com elas. As duas formaram famílias, estão superbem. Tem uma boa parcela deles que tentaram buscar uma modificação nas suas vidas, mas a questão da saúde terminou não permitindo. O que se percebe agora, com a questão do crack, é que não está se trabalhando com isso especificamente. A redução de danos é isso na nossa vida, é se desprender de algo que está nos prejudicando, é a transformação. A pessoa se transforma, desde que ela tenha um pensamento do que ela quer. Enquanto a gente não trabalhar com a questão da reflexão... Eu vou responder o que a Marta Conte uma vez me questionou: "Tu refletes, e essa sensibilização, é o quê?" É quando o sujeito, após o uso abusivo, se sensibiliza com a sua problemática. Isso fui eu que criei. Como é que tu vais criar uma metodologia sem refletir? Sem te sensibilizar e te conscientizar do teu problema? Tu só vais criar um mecanismo e conseguir te compor dentro daquilo que tu estás criando como meta e a partir disso. Eu vou puxar o freio, porque eu refleti, eu me sensibilizei com aquilo tudo que eu estou passando.

\section{E como é que o redutor opera para conseguir ajudar a produzir isso no usuário?}

Eu converso muito. Com alguns, entra num ouvido e sai no outro, porque o contexto dele é aquilo ali. Tem a questão da família, tem a questão de se já estiveram em abrigos, uma série de coisas. Então é difícil, quando tu não tens nada para oferecer, eles pararem para te escutar.

\section{E tu achas que quando tinha seringa fazia diferença nisso?}

Sim. Era o que chamávamos de ferramentas de aproximação. A gente tentou com os cachimbos, projeto-piloto e tal, só que não deu certo, eram muito grandes. Foram cinco estados onde foi implantado esse projeto-piloto. Me passaram uma quantidade de cachimbos, não funcionou em lugar nenhum. O que agora pode ser a ferramenta de aproximação é o protetor labial, a piteira, o canudinho do cachimbo, essas coisas.

Então, tu pensas que o insumo é um meio de aproximação para chegar num vínculo que possibilite reflexão, sensibilização e conscientização?

Sim. Se tu não tiveres algo para fazer uma troca..., porque a RD que a gente sempre trabalhou é uma troca. Apesar de que a seringa a gente não trocava, a gente disponibilizava. A gente usava a ferramenta de aproximação. A partir do momento em que a gente se aproximou, viu que ele faz uso e que é uma pessoa de risco no compartilhamento, a gente trabalha essa questão com ele. 
E, atualmente, tu sabes alguma coisa de RD acontecendo?

Eu vejo no Centro de Atenção Psicossocial (Caps) e nos consultórios Da Rua e Na Rua, eu tenho brigado por esses espaços. Eu fui a Livramento (RS), fiquei uma semana no Caps de lá. A gente fez busca ativa, fez contatos, entre outras coisas. Os grupos dentro dos Caps trabalham com a questão do crack. Eles não exigem abstinência. Olha, eu tenho brigado por esses dois espaços: os Caps e os consultórios Na Rua. Esses são os nossos lugares!

\section{NOTAS}

${ }^{1}$ Pequeno aparelho com um sistema interno moedor ou triturante, utilizado para preparar o tabaco ou outros tipos de fumo para posterior confecção de cigarros.

${ }^{2}$ Local de consumo de drogas ilícitas em cenas públicas de uso.

\section{REFERÊNCIAS}

ADAMY, Paula; SILVA, Rosane Neves da. Redução de danos e linha de cuidado: ferramentas possíveis para o cuidado em saúde mental, álcool e outras drogas In: Torossian, Sandra; Torres, Samantha; Kevler, Daniel Boianovsky. Descriminalização do cuidado: políticas e cenários e experiências em redução de danos. Porto Alegre: Editora da UFRGS, 2017. p.145-158.

BRASIL. Ministério da Saúde. Secretaria de Vigilância em Saúde. Departamento de Vigilância, Prevenção e Controle das Infecções Sexualmente Transmissíveis, do HIV/Aids e das Hepatites Virais. Agenda estratégica para ampliação do acesso e cuidado integral das populações-chave em HIV, hepatites virais e outras infecções sexualmente transmissíveis. Brasília: Ministério da Saúde, 2018.

BRASIL. Ministério da Saúde. Secretaria Executiva. Coordenação Nacional de DST/Aids. A política do Ministério da Saúde para atenção integral a usuários de álcool e outras drogas. Brasília: Ministério da Saúde, 2003.

KLEIMAN, Mark; HAWDON, James (ed.). Encyclopedia of drug policy: "the war on drugs", past, present, and future. Thousand Oaks: Sage, 2011.

PETUCO, Dênis da Silva. O pomo da discórdia? Drogas, saúde, poder. Curitiba: Editora CRV, 2019. 